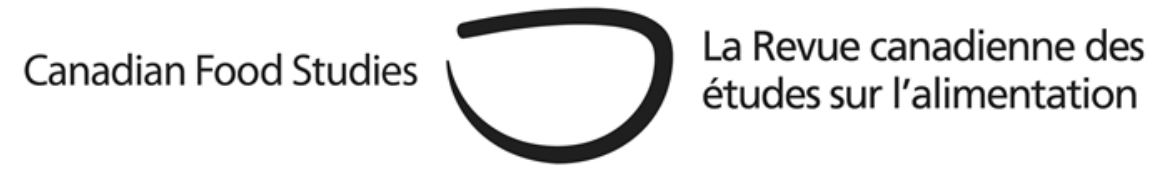

Original Research Article

\title{
Modularity in intersectoral research/action collaborations for food systems transformation: Lessons from the FLEdGE community- engaged network
}

\author{
Charles Z. Levkoe ${ }^{a^{*}}$, Alison Blay-Palmer ${ }^{b}$ Irena Knezevic ${ }^{c}$, David Szantod, Nii A. Addye \\ a Lakehead University

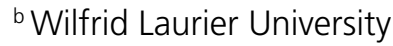 \\ ${ }^{c}$ Carleton University \\ dUniversity of Ottawa \\ e McGill University
}

\section{Abstract}

How can academics and community practitioners better collaborate to overcome the existing barriers? What role can intersectoral research collaboratives play in supporting, enhancing, and sustaining the impact of community-engaged research? In response to these broad questions, this paper shares insights from the Food: Locally Embedded, Globally Engaged (FLEdGE) community-engaged research network, a collaborative, interdisciplinary group of scholars and practitioners that crossed sectors, scales, and geographies. The FLEdGE research program ran from 2015 to 2021, and built on over a decade of academic and community partnerships to assess the current and potential role of food initiatives as pillars for sustainable transformation. Our mixed-methods study draws on data from a social network analysis survey, summary reports, semi-structured interviews, and reflections from the authors who were all active members of the network. Our findings reveal that beyond making theoretical and practical contributions to food systems scholarship and initiatives in the participating regions, FLEdGE played an important role in building food movements across Canada and beyond. We describe this as a modular approach, an organizational structure in which multiple units (or modules) operate independently while also sharing enough commonalities that allow them to be interrelated, modified, and reconfigured in diverse and dynamic ways. 
We argue that intersectoral research networks adopting a modular approach require interdisciplinarity and collaborative methodologies, but also flexibility and critical reflexivity. In addition, we underscore that setting objectives, both overarching and tactical, requires a negotiated approach, particularly when budgetary administration resides within an institutional partner.

Keywords: Community-engaged research; FLEdGE; food systems; modularity; social network analysis

\section{Introduction}

Critical research focusing on equitable and sustainable food systems has grown dramatically over the past decades. Numerous studies have documented the enhanced impacts of intersectoral and engaged research approaches with academics working alongside practitioners and activists towards common goals (Wakefield, 2007; Levkoe et al., 2016; Knezevic et al., 2017; Reynolds et al., 2018). However, this work has been limited by institutional barriers, including disciplinary and sectoral pressures such as limited funding for community participation and little acknowledgement or reward for academics (Changfoot et al., 2020), a distrust of academics and their institutions (Dempsey, 2010; Bortolin, 2011; Kepkiewicz et al., 2018), along with limited time and resources to pursue this kind of work (Israel et al., 1998). These challenges demand that academics involved in community-based research consider ways to overcome existing barriers.

In response to these broad challenges, this paper shares insights from the Food: Locally Embedded, Globally Engaged (FLEdGE) community-engaged research/action network, a Canada-based, interdisciplinary group of scholars and community-based practitioners from across sectors, scales, and geographies. ${ }^{1}$ FLEdGE built on over a decade of prior partnerships among academic, public, private, and non-profit actors and was established as a limited-term research collaboration funded by the Social Science and Humanities Research Council of Canada (SSHRC) from 2015 to 2021. It aimed to assess the current and potential role of community food initiatives as pillars for sustainable transformation. Through FLEdGE, the partnerships evolved and led to new networks, thus extending collaboration beyond the grant.

The research for this paper asks: What role can intersectoral research collaboratives play in supporting, enhancing, and sustaining the impact of community-engaged research?

\footnotetext{
${ }^{1}$ More information about the FLEdGE network including details about its structure, governance, outputs, and outcomes are available at https://fledgeresearch.ca/.
} 
Our mixed-methods evaluative study draws on data from a social network analysis (SNA) survey of FLEdGE participants, summary reports submitted by each of the research teams and working groups, project outputs, semi-structured interviews with academics and community-based practitioners engaged in FLEdGE, and reflections from the authors who were all active academic members of the FLEdGE network. ${ }^{2}$ This research takes a macro view of the FLEdGE network, drawing on and combining different methods to provide a portrait of one intersectoral research collaboration with the goal of food systems transformation. Our findings reveal that beyond making theoretical and practical contributions to food systems scholarship and initiatives in the particular regions, FLEdGE played an important role in expanding networks across Canada and beyond. This paper is part of a themed issue of Canadian Food Studies that includes contributions from across the FLEdGE network, providing further examples of specific projects, impacts, and outcomes.

Reflecting on the insights revealed by our research, we propose that research and action collaboratives aiming to build more equitable and sustainable food systems take a modular approach. The extensive body of literature on modularity spans numerous themes, ranging from product and service design to organizational management to the behaviour of complex systems (Baldwin \& Clark, 2000; Frandsen 2017; Newman, 2006). For the purposes of this paper, we interpret modularity as an organizational structure in which multiple units (or modules) operate independently while also sharing enough commonalities that allow them to be interrelated, modified, and reconfigured in diverse and dynamic ways. It implies a selective use of the different pieces of the whole, which allows for nimbleness and flexibility. As the FLEdGE network evolved, it embraced a set of practices that can be interpreted as a modular approach to both research methods and outputs. Although modular design was not an intentional aspect of the original organizing structure, its emergence over time serves as the frame we have adopted for our analysis, and usefully works to describe our collective insights. We suggest that intersectoral research networks adopting a modular approach require interdisciplinarity and collaborative methodologies, but also the flexibility and critical reflexivity of decision-makers to allow for emergent approaches (Snowden \& Boone, 2007), as was the case for FLEdGE.

We begin by reviewing literature discussing intersectoral research collaborations and insights for scholars and practitioners engaged in food systems research. The authors of this paper are actively engaged in such research and we draw, in part, on our own scholarship as a foundation for collective reflection. Next, we describe the context and evolution of the FLEdGE network and present our findings in three distinct sections: SNA, FLEdGE outputs, and interview data.

\footnotetext{
${ }^{2}$ Alison Blay-Palmer was the primary applicant of the SSHRC grant and the Director of the Laurier Centre for Sustainable Food Systems, which hosted the FLEdGE project. Charles Levkoe and Irena Knezevic were coapplicants of the SSHRC grant and active in the Northern and Eastern Ontario nodes respectively. Nii Addy was a member of the Quebec node that was developed from the grant, linking to other networks, and David Szanto joined FLEdGE as a postdoctoral fellow in 2019 to support research and evaluation of the network.
} 
Following the model of modular design that recognizes modules as both interdependent and complementary, each section aims to show different yet interdependent portraits of FLEdGE. We end with a reflective discussion and share recommendations for future research and practice.

Intersectoral research collaboration and food systems scholarship

In the context of this paper, we use the term intersectoral research collaborations to describe a range of engagements between academics (e.g., students, faculty, and research staff) and practitioners (e.g., public, private, and non-profit actors). These collaborations may take the form of formal research projects that consider a series of ideas, investigate a specific problem, and/or engage in an action-oriented initiative with goals of social change. They go far beyond holding joint meetings or consultations and can range from sharing ideas to active knowledge co-creation (Katz \& Martin, 1997). We adopt Strand et al.'s (2003) description of meaningful partnerships as ones that "collaboratively engage in research with the purpose of solving pressing community problems or effecting social change" (p. 3). In addition, we draw insights from studies that approach engaged research as relational and mutually beneficial (Israel et al., 1998; Strand et al., 2003). Further, we agree with critical scholars who suggest that effective collaborations must challenge dominant power relations that are embedded in the research process itself (Curwood et al., 2011; Jagosh et al., 2015; Taylor \& Ochocka, 2017). When done well, intersectoral research collaborations provide new opportunities to address pressing social challenges by bringing together unique and innovative knowledge, skills, and tools (Schwartz et al., 2016, p.178).

Institutions that broker such collaborations play an important role in sustaining projects over time and supporting participants from conception and design to implementation and knowledge mobilization (Tennyson, 2014). They can be integral in promoting learning across the network and negotiating power imbalances among those involved (Keating \& Sjoquist, 2000; Phipps et al., 2015). Exploring the characteristics of different models for supporting intersectoral research collaboration, Levkoe and Stack-Cuttler (2018) reviewed the literature along with a range of examples from Canada, the US, and the UK to reveal that there is no single or universal approach that will guarantee success. Instead, approaches must be context-specific and responsive to the shifting needs and assets of the varied partners involved. This finding does not negate the need for tools to support collaborations in more deliberate ways. In our research on the FLEdGE network, we recognize that the wide range of structures, compositions, and purposes of intersectoral research collaborations can complicate a systematic study, yet we suggest that their diversity and complexity is part of what makes them so promising.

The value and impact of research collaborations cannot be quantified in a straightforward way (Beckman et al., 2011; Greenhalgh et al., 2016; Levkoe \& Kepkiewicz, 2020). 
While some outputs can be immediately observed and measured (e.g., the number of multiauthored publications, research grants received, people engaged), the value of intersectoral research collaborations and their related outcomes are often intangible in the short-term (Goemans, 2018; Peacock et al., 2020). Collaborations that begin at the conceptualization and design phase have been shown to encourage more respectful relationships (Bringle \& Hatcher, 2002; Ochocka \& Janzen, 2014). Involving community-based practitioners as partners during the early stages of a project and continuing throughout the research process can improve knowledgesharing and problem-solving capabilities (Lindamer et al., 2009). Intersectoral research collaborations can produce new and sometimes unexpected perspectives that increase knowledge generation (McNall et al., 2009). Additionally, such collaborations can generate new opportunities for experiential learning and student training by enabling the application of theoretical concepts and strengthening leadership capacities inside and outside the academy (Chupp \& Joseph, 2010). This is particularly valuable for food systems work, in which boundaries between scholarly and applied efforts can be porous (Frank, 2014; Bradley et al., 2018).

Intersectoral research collaborations can lead to mutually beneficial outputs and outcomes (Levkoe et al. 2016; Naqshbandi et al. 2011). Beyond contributions to academic literature and theory, deeper engagement can lead to high-impact applications of research findings. For example, Savan and Sider (2003) show how a large-scale intersectoral research collaboration brought together academics, practitioners, universities, research centres, and nonprofit organizations to build capacity for increased sustainability initiatives in the city of Toronto. Using multiple forms of community-engaged research, this took the form of new working relationships as well as a diverse range of scholarly and practical benefits, including enhanced social and economic community development. Other demonstrated benefits from intersectoral research collaborations include building capacity for under-resourced communitybased organizations (Baquet, 2012; Sandy \& Holland, 2006), sustaining relationships beyond the life of a project (Naqshbandi et al., 2011), and increasing potential to challenge inequitable power dynamics in society while encouraging systemic change (Marullo \& Edwards, 2000; Sheridan \& Jacobi, 2014). Intersectoral research that draws upon the perspectives of diverse stakeholders recognizes the complexity of societal problems, moving beyond the misdiagnosis of such problems as "complicated" ones (Snowden \& Boone, 2007), with the "expert" versus "beneficiary" approaches that have historically characterized social science research. The work of 2009 Nobel Economics laureate, Elinor Ostrom, is illustrative of such intersectoral efforts (Ostrom, 2010), which shift attention from expertise and predictive analysis to privilege-probing and broad stakeholder engagement, often using qualitative approaches for diagnostic analysis (Addy et al., 2014).

Despite these documented benefits and opportunities of intersectoral research collaborations, there are limitations and barriers that inhibit more widespread success including high time, financial, and human resource requirements. 
Costs can include having to share already limited resources, additional travel, limited capacity to fully engage in regular communication, negotiations and conflict resolution, and increased administration requirements (Dorow et al., 2011; Petri, 2015; Sandy \& Holland, 2006).

Disciplinary and sectoral pressures faced by both researchers and practitioners also present limitations. Post-secondary faculty face a growing set of professional expectations to meet particular standards. These expectations are often increased by taking on collaborative research projects. For example, research findings rarely fit comfortably into existing structures dictated by discipline-specific departments and scholarly journals (Checkoway, 2015; O'Meara et al., 2015). A reflective essay by Changfoot et al. (2020) demonstrates ways in which collaborative and engaged research has an impact on faculty at all stages of tenure and promotion, arguing for academic institutions to better recognize and support these initiatives (also see O’Meara et al., 2015; Sobrero \& Jayaratne, 2014). Further, many community-based practitioners and non-profit organizations have limited capacity and resources to take on research-related projects, due, in part, to funding obligations and pressure to address immediate social needs (Incite! Women of Colour Against Violence, 2007).

Another limitation relates to the historical and ongoing experiences of distrust between academics and community-based practitioners (Lantz et al., 2001; Petri, 2015). Post-secondary institutions legitimize and centre academic knowledge and associated modes of knowledge production over other ways of knowing (Smith, 2002; Hart et al., 2017). In most cases, academics and their institutions are the primary beneficiaries of collaborative research projects (Ward \& Wolf-Wendel, 2000; Dempsey, 2010; Alcantara et al., 2015). Complicating matters are the power dynamics that favour academic over community interests and broader social needs (Bortolin, 2011; Curwood et al., 2011; Flicker, 2008; Sheridan and Jacobi, 2014; Vernon \& Ward, 1999), perpetuating dominant social relations that many projects aspire to address (Butcher at al., 2011; McBride et al., 2006; Varcoe, 2006). In a reflective essay about their engagement in a pan-Canadian intersectoral research collaboration, Kepkiewicz et al. (2018) recognize,

Despite our best efforts, we fell short of our aim to engage in research that benefited communities first and foremost. While emphasizing the importance of working towards 'community first' [intersectoral research collaborations], we are cautious of our ability to do so meaningfully in the present political and economic context where academic institutions privilege western and academic knowledge and expertise (pp. 45-46).

Furthermore, Grain and Lund (2016) argue that the work of intersectoral research collaborations are too often "steeped in a history of White normativity and charity" (p. 46).

The studies identifying both opportunities and limitations of intersectoral research collaborations are particularly insightful for scholars and practitioners engaged in food systems projects. As an evolving field, food systems scholarship demands interdisciplinarity, community engagement, and critical perspectives. 
It is a dynamic and evolving assemblage of theories and approaches that use food as a lens to understand a wide range of social and ecological issues (Albala, 2013; Atkins \& Bowler, 2016; Brady et al., 2015). Koç et al. (2016), explain, "food studies focuses on the web of relations, processes, structures and institutional arrangements that cover human interactions with nature and other humans involving the production, distribution, preparation, consumption, and disposal of food" (p. xiv). Intersectoral research collaborations have not only been embraced by food systems scholarship but have also been instrumental in the development of the field. Through the Community First, Impacts of Community Engagement (CFICE) partnership project, partners working on food sovereignty projects described the establishment of a community of practice that contributed to research, teaching, and action. Levkoe and Kepkiewicz (2020) explain:

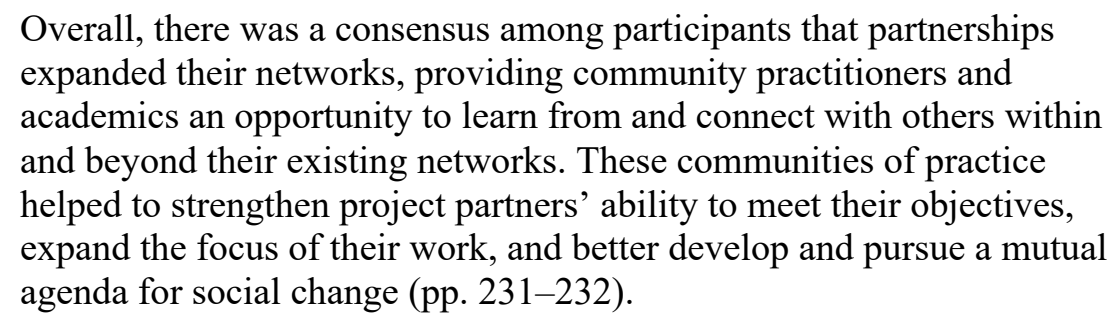

In another study of the CFICE project, Levkoe et al. (2016), argue that "when it is part of relationships based on mutual benefit and reciprocity, [community-campus engagement] canand does - play an important role in building food movements" (p. 32). Further, Andrée et al. (2016) explain that the CFICE partnerships provided academics with new insights about ways to critically engage in food studies research, teaching, and action.

It is within this broader context of intersectoral research collaborations and food systems scholarship that the FLEdGE network was embedded.

\section{The FLEdGE community-engaged research/action network}

The FLEdGE network was established in 2015, when a group of community and academic researchers secured a Partnership Grant from SSHRC. Hosted by the Laurier Centre for Sustainable Food Systems, FLEdGE brought together numerous existing collaborations and projects from across Canada and internationally to create an intersectoral research/action network. This pre-existing work cemented the core principles of FLEdGE, a commitment "to fostering food systems that are socially just, ecologically regenerative, economically localized and that engage citizens" (About FLEdGE, n.d.). As part of the grant application, members collectively agreed on three broad areas to guide the action-research projects: 1) Integration across multiple political jurisdictions (municipal, regional, national, international), policy spheres (e.g., economic development, agriculture, the environment), and sectors (public, private, civil society); 
2) Exploring and addressing tensions, compromises, and opportunities inherent in the scaling up and out of sustainable food system initiatives; and 3) The need for appropriate, innovative governance structures and institutions to support the development of sustainable regional food systems. The FLEdGE network set out to explore and document ways that community knowledge was being shared among the existing initiatives, opportunities for that knowledge to be adapted to place-specific needs and conditions in other communities, and opportunities for knowledge to inform theory and scholarship on food systems.

The FLEdGE network comprised over 50 partner organizations, including non-profits, public sector practitioners, universities and research centres, and co-ops and small businesses. The original configuration included eight regional nodes in Canada - four in Ontario and one each in the Northwest Territories (NWT), Alberta/British Columbia, Quebec, and Atlantic Canada. As work progressed, two Ontario regional nodes (southern and southwestern Ontario) merged. The nodes functioned autonomously while looking for points at which research initiatives intersected. Examples of this included: the use of the Open Food Network platform, developed as part of the southern Ontario node, which was then taken up in northern Ontario; Indigenous food systems initiatives with intersections between NWT and northern Ontario; development of a food policy database in British Columbia, later adapted in Alberta and Ontario; and the creation of the pan-Canadian Food Counts metrics project, which mobilized food systems indicators using a food sovereignty framework. The group committed to ongoing reflexive assessment of the research and networking processes using SNA and other evaluative tools.

In the first and second year of FLEdGE, international working groups emerged organically at the intersection of the core themes and ongoing international research collaborations and initiatives. One international working group focused on innovative governance (Andrée et al., 2019), and a second focused on food system metrics and tools (BlayPalmer et al., 2019). A third working group on agroecology included an agroecology field school and research summit held in 2016 and 2018 (Laforge et al., 2020).

The FLEdGE network's structure and governance were emergent and evolved over time. While the collaborative research/action network began with a group of existing partners, these relationships grew to include new engagements, as individuals were added, and research and action initiatives expanded. Over time, the FLEdGE core team, made up of leads from the regional nodes, worked to support the different components of the collective work, acting as a "backbone organization" (Kania \& Kramer, 2011). Decisions about funding and project direction were made collectively by the core team, and a project coordinator was hired to support the node's research and reporting, along with overall administration. Meetings were held monthly through video calls to discuss node progress, priorities, and directions. Through these discussions, there were opportunities to identify collaborative research projects and engage in joint outputs. Face-to-face meetings were organized at annual conferences, in particular as part of the annual meeting of the Canadian Association for Food Studies (CAFS). 
Findings: Portraits of the FLEdGE network

Our findings from research with the FLEdGE network encompass quantitative and qualitative data. We highlight the network's evolution based on two SNA surveys, FLEdGE outputs, and qualitative interviews with members of the network.

\section{Social network analysis}

To conduct a SNA of the FLEdGE network, surveys were circulated twice, in 2015 (response rate of 55\%), during the first year of the network, and again in 2018 (response rate of 59\%). The surveys were sent by email to all active members of the network, based on lists held within the FLEdGE database and confirmed by the node leaders. Data were collected and analyzed in relation to three relationship categories: communication (i.e., in person, by phone, or by email), work-related collaboration, and referential relationship (i.e., using the specified individual's program, research). All ties were directed, meaning that each connection in the network specified who was identifying the relationship (vs. only indicating that a relationship existed).

Overall, the FLEdGE network more than doubled in size over four years. The percentage of strong communication, collaboration, and referential ties increased significantly. The percentage of weak ties decreased across all three categories. For the network visualizations in Figures 1 and 2 below, we highlight affiliation (i.e., university, community) and regional grouping (i.e., Ontario, Canada outside of Ontario, international). The 2018 data suggest that university-affiliated network members were more likely to communicate with, collaborate with, and reference other university members than they were with community members. The likelihood of communication, collaboration, or referential ties among members of the same region and between members of different regions were much higher than expected. In the following subsections, we present some of the most salient findings from the SNA.

\section{Communication, collaboration, and referential categories}

Overall, the size of all three networks in the relationship categories increased between 2015 and 2018. The number of nodes, being the number of actors in the pre-defined network, increased from 80 in 2015 to 162 in 2018. The total number of communication and collaboration ties, or the total number of reported communications and collaboration connections between nodes, doubled over the same period, from 1466 to 2899 , and from 910 to 1967 respectively. The total number of referential ties between nodes in 2018 (2386) was almost three times that of 2015 (875). 
The quality of the ties also grew stronger over time. For example, the percentage of strong and moderate communication ties (as rated by respondents) increased, from 15\% and 22\% respectively in 2015 to $21 \%$ and $28 \%$ in 2018 , a finding consistent with the evolution of collaboration and referential ties. The whole communication, collaboration, and referential networks, including all reported respective ties in 2018 are illustrated in the sociograms in Figure 1.

Figure 1: Sociograms, whole network including all reported

Figure 1.1: Communication ties

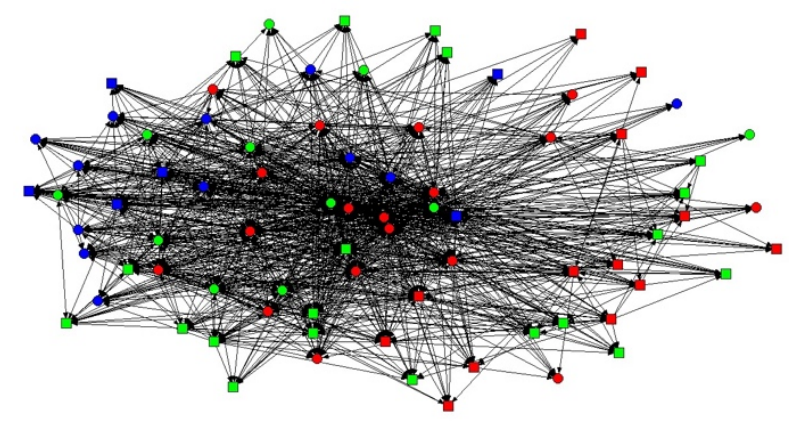

Figure 1.2: Collaboration ties

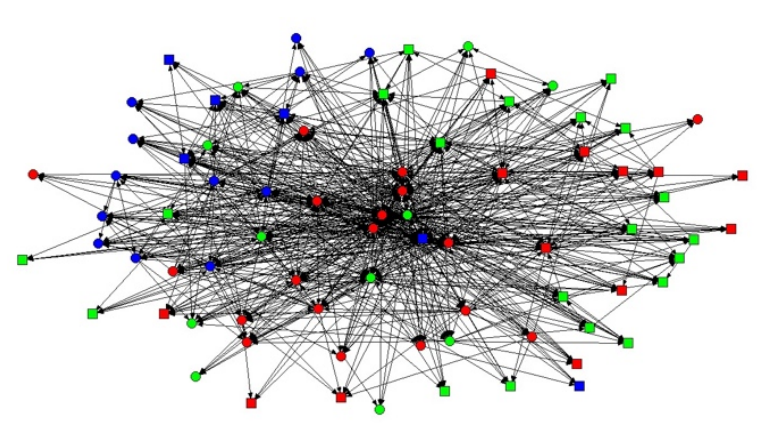

2018

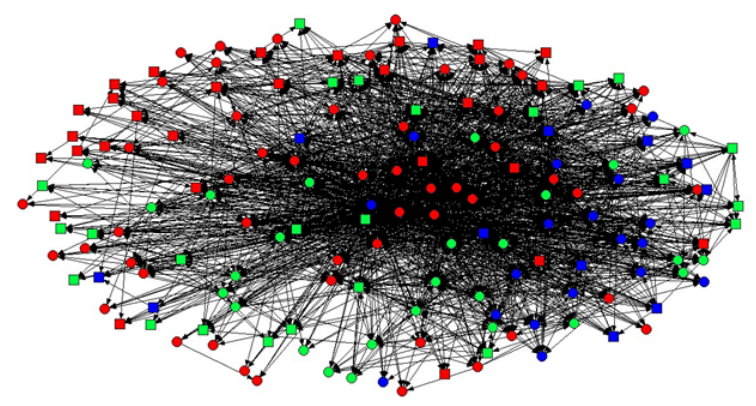

2018

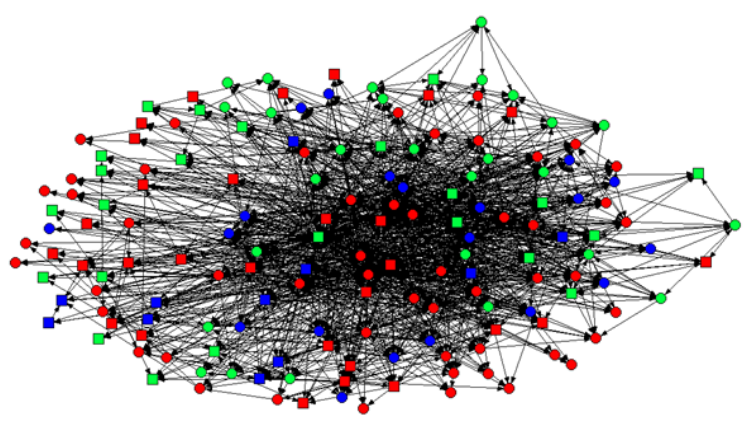


Figure 1.3: Referential ties

2015

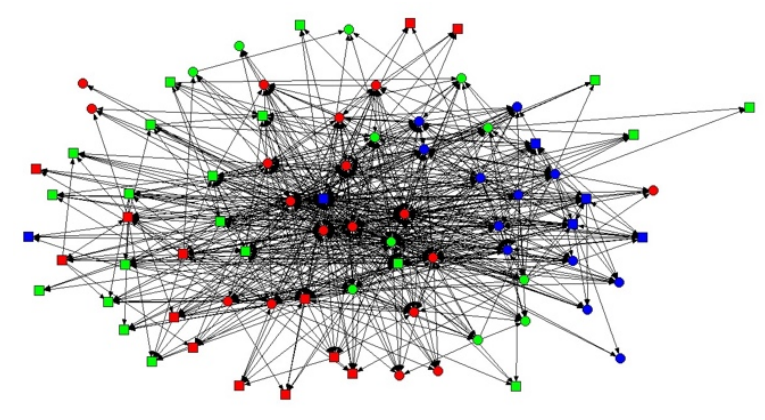

2018

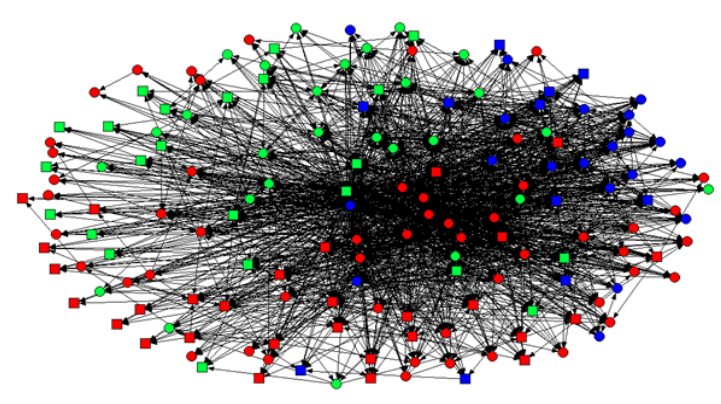

Circle $=$ University affiliation

Square $=$ Community affiliation

Red $=$ Ontario

Green $=$ Canada outside of Ontario

Blue $=$ International

Measures of centrality and cohesiveness indicated that communication, collaboration, and referential ties evolved over time. For example, a closer look at relationships among those who indicated strong ties yielded additional insights. There was a decrease in centralization-a measure of how central the most central node is in relation to how central all the other nodes are - of the communication ties (from 0.561 in 2015 to 0.247 in 2018), collaboration ties remained relatively stable (from 0.299 in 2015 to 0.294 in 2018), and the referential ties became more centralized (from 0.310 in 2015 to 0.337 in 2018). The ties that were reported as strong for communication, collaboration, and referential networks in 2018 are illustrated in the sociograms in Figure 2. 
Figure 2: Sociograms, whole network including only strong ties

Figure 2.1: Communication ties

2015

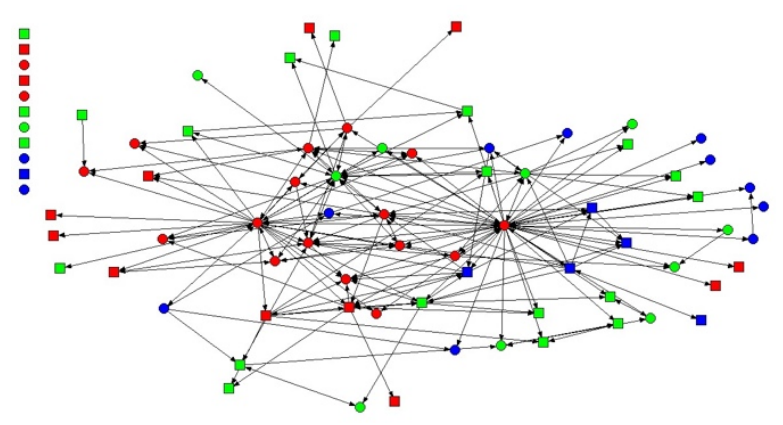

\section{8}

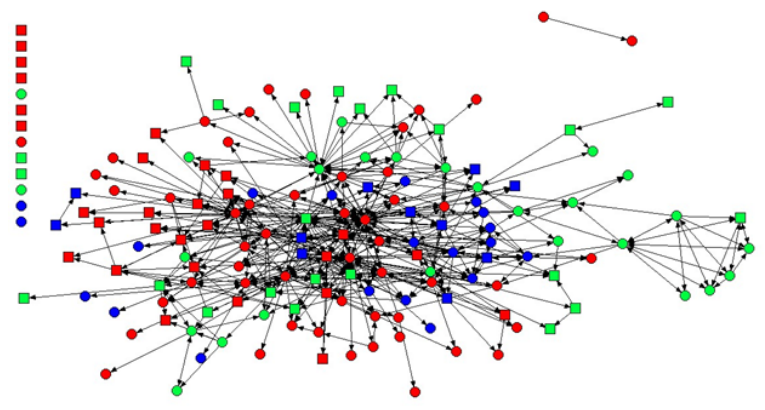

Figure 2.2: Collaboration ties

2015

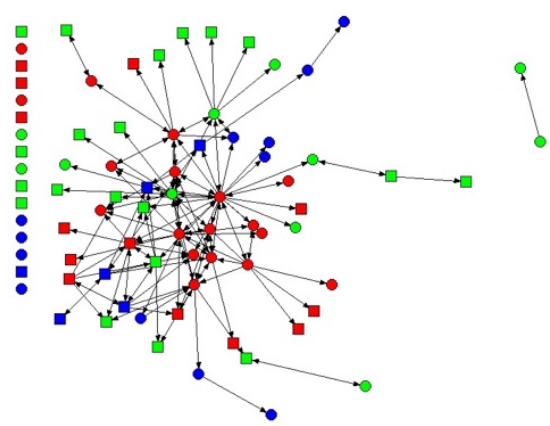

2018

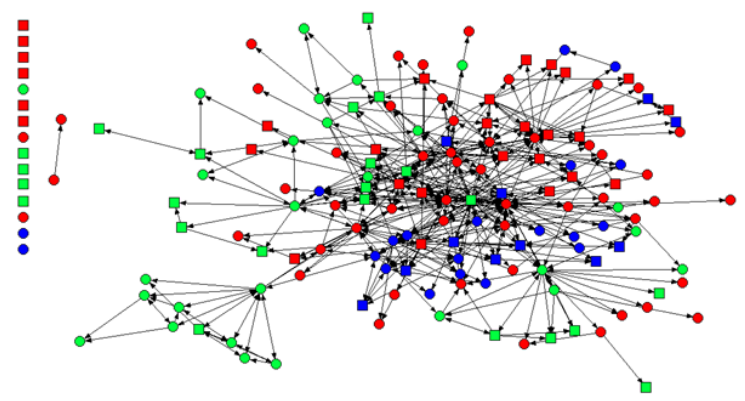


Figure 2.3: Referential ties

2015

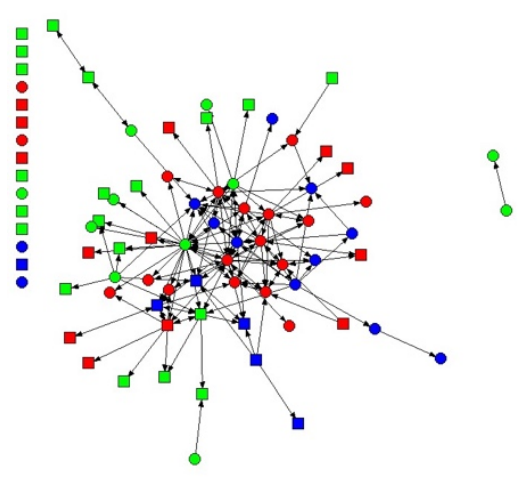

Circle $=$ University affiliation

Square $=$ Community affiliation

Red $=$ Ontario

Green $=$ Canada outside of Ontario

Blue $=$ International
2018

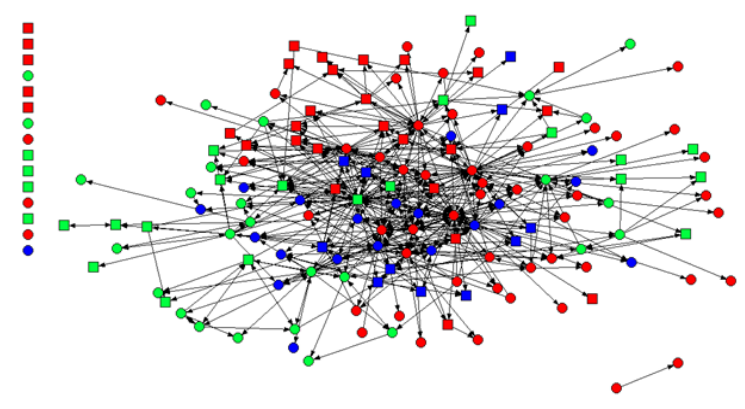

\section{Tests of correlations}

Three types of correlations were tested in each of the three relationship categories. First were tests of whether the density of communication, collaboration, and referential ties within and between two groups (university and community) differs from what we would expect if ties were distributed at random across all pairs of nodes, and we found significant differences. We found evidence of homophily - that is, university-affiliated network members are more likely to communicate and collaborate with, as well as reference, other university-affiliated network members than with community members. Further, we found that communication, collaboration, and referential ties between university-affiliated members and community members are less likely than random, rather than more likely. Ties between actors who share the attribute of community affiliation are also less likely than random.

Second were tests of whether ties within and between three regional groupings differed from what we would expect if ties were distributed at random across all pairs of nodes. We found no significant differences. Third were tests of correlation that showed the density of communication, collaboration, and referential ties within and between the regional nodes differed in some cases from what we would expect if ties were distributed at random across all pairs of nodes. While we found that "additional in Canada" showed homophily with all other regions, not all other regions were reciprocal. 
From a broader perspective on the overall network characteristics, we focused on the findings of ties between university- and community-affiliated from the three sets of correlation tests. While FLEdGE has provided a means for communication, collaboration, and referential ties, the finding that ties between the two types remain less likely than those between academics suggests the potential for even greater levels of collaboration.

Next, our analysis of project outputs shows how FLEdGE members are creating value and suggests opportunities for further leveraging ties between academic and community members.

\section{FLEdGE outputs}

The outputs from the FLEdGE network illustrate the quality, flexibility, and impact of the communication, collaboration, and referential ties among members, and other aspects of the partnerships. Throughout the grant's tenure, FLEdGE node leads gathered information about contributions and productivity, including in-kind and cash contributions, academic publications, reports, presentations and workshops, meetings, student engagement and training, and other outputs from the various subprojects. The FLEdGE administrative coordinator gathered the impact measures from each node three times a year and consolidated them annually. Knowledge sharing among partners and beyond the FLEdGE network was at the heart of the work. FLEdGE relied on a community-engaged, participatory approach to research that included 132 individuals and 89 organizations. By August 2020, ${ }^{3}$ FLEdGE had generated 720 informational outputs, including 80 peer-reviewed journal papers (42 open access), 313 presentations, 41 interviews in print or broadcast, 43 book chapters, four open access books, 93 reports and briefs, 14 online tools, 29 videos, 14 infographics, and dozens of blog posts and popular articles. In 2019, FLEdGE launched a podcast series called Handpicked: Stories from the Field, which reports on the research and action of network members and partners. Furthermore, FLEdGE had attracted more than $\$ 4.7$ million in matching contributions from partners and other supporters.

Each node and working group reinforced existing partnerships and built new connections that aimed to extend into the future through the creation of community relevant tools, resources, and capacity building. There are several examples that demonstrate the place-based differentiation of the FLEdGE research projects. In the NWT, on-the-land camps focused on intergenerational knowledge exchange, mapping changing landscapes to help ensure harvester safety in the context of climate change, and on-going discussions about whether growing food as a complement to traditional food systems is culturally and logistically appropriate (Simba \& Spring, 2017).

\footnotetext{
${ }^{3}$ At the time of writing, results up until August 2020 were available. Most outputs are available on the FLEdGE website (https://fledgeresearch.ca/).
} 
At the national scale, Food Counts, the pan-Canadian report card on sustainable food systems, drew on principles of food sovereignty and integrated existing indicators from across multiple sources (including Statistics Canada) to benchmark the extent of sustainability for Canada (Levkoe \& Blay-Palmer, 2018). It also pointed out where information is lacking, for example in trying to understand the idea of valuing food as sacred, especially from an Indigenous perspective (Levkoe \& Blay-Palmer, 2018). Other examples include: Kwantlen Polytechnic University's food policy database and bioregional food self-reliance modelling; working with Food Secure Canada (FSC) and other food movement actors to provide input into the creation of a national-level Food Policy for Canada (Levkoe \& Wilson, 2019); co-creation, with international partners, of a sustainable food systems toolkit (Blay-Palmer et al., 2018); creation of innovation impact mapping methodology with the French Agricultural Research Centre for International Development in fourteen urban food innovation labs (Valette et al., 2020); the creation of food system support tools, including maps for the Good Food Market Expansion Explorer; support for establishing the Indigenous Food Circle, made up of 22 Indigenous-led and Indigenous-serving organizations addressing food sovereignty in northwestern Ontario (Levkoe et al., 2019); and a fish-as-food framework used to explore equitable and sustainable fisheries in the Lake Superior watershed and beyond (Levkoe et al., 2017; Lowitt et al., 2019).

Over time, given the diversity of projects and processes, a need arose to update the objectives of the FLEdGE network and make the underlying assumptions more explicit. A yearlong process of internal consultation and reflection ended with the identification and articulation of six Good Food Principles in 2019, all linked to existing evidence in the form of academic publications and community reports. The new principles were rooted in the overarching goal to build sustainable food systems for all, with a focus on six key areas: 1) Farmer Livelihoods, 2) Food Access, 3) Indigenous Food Sovereignty, 4) Ecological Resilience, 5) Sustainable Food Policy, and 6) Food Connections. ${ }^{4}$

Each of the sub-projects operated independently but also informed work in the nodes and working groups. For example, the NWT node worked with Indigenous communities at the intersection of climate change and traditional food systems. While this work was unique in the FLEdGE network, it played a role in other nodes' community-informed research and provided examples to international partners. Two projects in British Columbia are also illustrative. In the first instance, an online policy database was created for the province that was searchable across several topics (e.g., land use, food supply chains, Indigenous food systems) and scales. The database was adopted for use in Alberta and is being adapted to Ontario. Second, academics at Kwantlen Polytechnic University led a COVID-19 food purchasing survey that was developed for British Columbia and was taken up by FLEdGE partners in Ontario, Quebec, and Atlantic Canada. These projects all demonstrate place-based diversity typical of community-defined research, as well as the capacity to be adapted in other locales.

\footnotetext{
${ }^{4}$ The Good Food principles are described in more detail at https://fledgeresearch.ca/.
} 
The high quality and quantity of outputs illustrate what the network generated, and despite institutional pressures towards more traditional kinds of scholarship, included a wide range of audiences, formats, and venues.

\section{Interviews}

To add to the portrait of FLEdGE, sixteen semi-structured interviews with network members were conducted in early 2020 to qualitatively complement the review of SNA and outputs. The questions focused on the extent to which the interviewees had witnessed change in both the network and themselves over the course of their engagement. Participants were selected using the 2018 SNA results, and they represent a heterogeneous sample (e.g., university-affiliated, community partners, Canadian, international) and a range of depths of engagement (e.g., strong, moderate, minimal). Through member checking, participants were given the opportunity to review the notes and recordings from their interview and to request clarifications if needed. Transcripts were coded thematically, and a synthesis of the results are presented in this subsection using four broad categories that capture the overarching sentiments of participants.

\section{Objectives and change}

Participants who had been involved with FLEdGE for several years noted positive types of change within the network, including the evolution of the stated and actualized objectives, the style and logistics of governance and decision making, and the qualitative nature of interpersonal relationships. Many addressed the potential and expectations for ongoing work, whether formally or informally related to FLEdGE. While one interviewee referred to this as "FLEdGE 2.0," another noted that 'it's not FLEdGE 2.0, and shouldn't be FLEdGE 2.0, it's fledglings 2.1, 2.3..." The latter framing was echoed by others who spoke of the foundation FLEdGE had provided to both themselves and their trainees to continue conducting community-engaged research. This sentiment was captured by one interviewee who had been a postdoctoral researcher during her engagement with FLEdGE: "There seems to have been quite a bit of capacity built among students, scholars, trainees, and community partners to move some of this work forward, even when this network of FLEdGE might not be funded any longer."

Those participants who had been involved with the network, both during and before FLEdGE was established, noted that the objectives had transformed over time, and that this was viewed as appropriate though potentially challenging. The initial objectives and key goals (eventually articulated as the Good Food Principles) lent a kind of personality to FLEdGE, one that generated a sense of connection and affiliation. As one international member stated, "There was this sense of 'We want to change the world...' I felt that we were all there trying to create something new, to create something good." 


\section{Increased breadth and diversity}

The widening scope of FLEdGE over time facilitated the development of relationships with some community partners, while potentially limiting the involvement of others. "We felt so welcome and so able to engage however we wanted to engage," said one community partner, "but in other ways, it was probably a turn-off for people who wanted to know immediately, 'Well, what are the objectives, and what do you need from me, and what's my deliverable and when do you need it from me?"' Community-based participants pointed to an appreciation of developing and sharing useful tools, stories from the field, and research reports, which established an understanding that project outputs need not be limited to academic publications. Instead, accessible outputs like videos, newsletters, report cards, and blog posts - in addition to conventionally published material—mobilized knowledge in ways that were meaningful and applicable to a wide range of practitioners.

Over time, FLEdGE's common objectives were variably interpreted, depending on the context and needs of the collaborators involved. For example, as the Canadian federal government ramped up efforts to develop the Food Policy for Canada in 2017, FLEdGE members were able to allocate time and resources to track, consult on, and influence these developments. The FLEdGE network provided a valuable support structure for such opportunities, and enabled network members - particularly those whose research partnerships extended across provincial and international borders - to identify more locally relevant, opportunistic, and actionable objectives.

In parallel to the diversification of objectives, participants noted that the network governance became more decentralized over time. The geographic reach of the network expanded outward from the initial centrepoint of Southern Ontario, toward the West, East, and North coasts of Canada, as well as Latin America and Europe. The activation of regional nodes became an opportunity for local leadership and decentralized research partnerships to establish themselves, resulting in what one participant named as a "federal-style" governance arrangement. This included a "FLEdGE HQ" and a set of "first ministers," who exchanged information and findings to reinforce the core functioning and directions for the network. Concurrently, each of the regional nodes was empowered to enact and achieve locally determined objectives, having been given the authority and budget to do so.

In counterpoint, one interviewee commented that the decentralization of objectives and governance made FLEdGE somewhat unclear and confusing. As an agricultural scientist, he acknowledged that this perspective may have been partly due to his disciplinary background, and that those in the social sciences may have been more comfortable with such decentralization, given their diverse methods and capacity for engaging with multiple foci. Several interviewees who were identified as community partners, however, noted that this approach made it possible for them to engage actively with collaborative projects while still meeting the objectives of their own organization, be it a municipal authority, a community non-profit organization, or a consulting practice. 


\section{A network of networks}

Interview participants repeatedly described the network as pluralistic. In the sense espoused by Bruno Latour and other post-actor-network theorists (Akama 2015; Latour 2005; Law \& Hassard, 1999), the FLEdGE network did not occupy a pre-determined structure, but instead represented a set of evolving relationships. Participants spoke about these relationships being activated towards emergent needs, whether research opportunities or occasions to produce actionable outputs. Equally, participants noted the latent potential of the network also engendered an intangible sense of self-empowerment, the exchange of scholarly and practical credibility, and the fundamental value of fostering trust among individual people, communities, and organizations. One participant expressed this value in terms of what FLEdGE did not become, invoking some of the structures into which other academic research efforts evolve, such as "teams", "centres", and "institutes." In her words, "FLEdGE was very, very effective on that front, and it was precisely because it was exactly a network, it was envisioned as a network, it acted like a network. And it did all the things that networks are supposed to do. It didn't try to become an 'institute'."

Participants in both academic and community sectors noted that being part of the network had lent credibility to their past and current work, as well as given them personal confidence for future initiatives. Several interviewees identified the value in being exposed to disciplinary practitioners outside of their field, including becoming comfortable with, for example, the discourse of social sciences or the notion of bioregional food systems. Resoundingly, both onthe-ground practitioners and scholarly researchers expressed the importance of learning to translate their experiences into theoretical and applied knowledge, the formulation of policies, and the surfacing of links and barriers among regional perspectives. Knowing that their immediate experience was locally relevant and globally understandable, as well as the fact that their context was both different from and similar to others, supported the potential for this crosssector translation.

\section{Blurred boundaries}

Participants' insights about the value of FLEdGE went beyond the immediate research results and actionable tools. They noted the network-of-networks approach, as team members occupied roles in multiple communities of practice. As a result, participants noted, they were able to crossfertilize methods, frameworks of knowledge, and perspectives, leading to broader change within FLEdGE, their other "part-time" communities, and themselves as sites of knowledge. Comments emphasized that FLEdGE will exist beyond its funded timeframe, serving as a resource that can be reactivated when needed. Many saw the network as a community of like-minded colleagues; FLEdGE created "a critical mass in Canada, there's power in that." 
Notable in a number of interviews was FLEdGE's generational impact on food research in Canada, particularly for the large number of graduate students and early-career researchers involved in and influenced by the network. Those with international experience also articulated that FLEdGE had highlighted the distinct threads of Canadian food scholarship and activism, including the importance of Indigenous partnerships and a focus on northern and First Nations food sovereignty.

The sociograms in the previous section offer a visualization of the growth of the FLEdGE network over time. Likewise, the description of the FLEdGE network's outputs provides an overview of some of the impacts of the collaborative, community-engaged research. Our interviews offer a complement, suggesting a decentralized governance structure and unbounded set of dynamics. Importantly, they also show ways that the relationships that made up the FLEdGE network pre-dated the formally funded research period, just as it is expected to persist into the future.

\section{Discussion: A modular approach}

Our combined findings demonstrate that the FLEdGE network has acted as a backbone organization to support, enhance, and sustain productive intersectoral collaboration and community-engaged research. It has generated flexible partnerships and facilitated productive collaborations that address at least some of the barriers previously identified in communityengaged research (Janes, 2016; Mullett, 2015; Stoecker, 2008). Network relationships in FLEdGE have intensified and expanded in ways that are both quantifiable and descriptive. FLEdGE has produced conceptual and theoretical insights as well as action-oriented initiatives, evident in the abundance of diverse research outputs and ultimately articulated in the six Good Food Principles. Beyond making theoretical and practical contributions to food systems scholarship and initiatives in the participating regions, the FLEdGE network connected to other networks to help build the food movement in Canada and beyond. The partnerships within the network were rooted in interdisciplinary, community-engaged, collaborative methodologies, flexibility, and critical reflexivity.

Our research suggests that taking a modular approach contributes to intersectoral research networks building more equitable and sustainable food systems. For FLEdGE, this included the diverse methodologies and methods that were accessible to both scholars and practitioners, and that were deployed in heterogeneous ways in response to different social and environmental contexts. Three main qualities of modularity inform our understanding of the way it played out within the FLEdGE network: 1) the capacity for modules to be arranged in new configurations while maintaining overall integrity of the network; 2) interfaces that allow modules to interact with and decouple from one another (including funding channels); and 3) the freedom for modules and their interfaces to be redesigned or discarded over time, in response to the evolving needs of project stakeholders (Campagnolo \& Camuffo, 2010). 
Accessible knowledge mobilization is an essential element of this approach, to ensure that research outcomes are meaningful to and actionable by all stakeholders (Phipps, 2011; Shields \& Evans, 2012). Comprising a modular research/action network, FLEdGE can also be conceived as a module itself, one that was, is, and will be a component of a much broader and ongoing series of initiatives, movements, and trajectories of change.

\section{Cross-pollination: Evolving network configurations}

In contrast with the stricter definitions of modularity put forth in product development, software design, and management discourse, the modular nature of the FLEdGE network was evident in how component parts evolved through their exposure to others. That is, rather than remaining static, the FLEdGE 'modules' (e.g., human, processual, discursive) changed over time. This played out at multiple scales - that of the network as a whole, as well as within nodes, teams, and individuals. Both the participants and their initiatives were able to absorb or reinterpret certain characteristics of one another, a kind of cross-pollination that resulted in valuable points of articulation among the modules. This included increased familiarity with theoretical and methodological frameworks outside of a given researcher's experience (in the case of academic participants), as well as greater understanding of the relationality between on-the-ground practice and scholarly analysis. It also extended to the identification of commonalities and contrasts among diverse forms of Indigenous experience, and to the exposure of international researchers to the food realities facing Indigenous communities. The latent potential for future success became evident as well, as modules have 'detached' from the FLEdGE network in order to recombine with other initiatives or spawn new modular networks of their own. This points to the positive, long-term effects that FLEdGE may continue to bring about, in part due to its structural design and emergent nature.

\section{Funding: Interaction and decoupling of modules}

Modularity, evident in the interactions and decoupling in the network, was nurtured through funding structures (from SSHRC and other leveraged resources), which also allowed for the scope of FLEdGE to be sustained and expanded. Not all partners participated equally across the entire lifespan of FLEdGE. Participation ebbed and flowed depending on such practical issues as staffing, other organizational priorities, and competing demands on participants' time (across all sectors). Nonetheless, the duration of funding as a key resource for sustained partnerships (see Israel, et al., 2006; Wright et al., 2011) and wide distribution of resources allowed for iterative and modular networking and collaboration. The network's connections with other organizations and groups, such as CAFS and FSC, facilitated greater reach to strengthen collaboration and mobilize findings. 
In addition, the SSHRC Partnership Grant was leveraged to secure additional institutional support, particularly within university settings. Upon reflection, the FLEdGE leadership also recognized that there may have been more opportunities to improve linkages with communitybased organizations and small businesses that are sometimes decoupled from research networks' financial support through budget allocations. Although SSHRC funding is subject to spending restrictions ${ }^{5}$, which limited FLEdGE's ability to offer monetary support to community organizations, network leads worked diligently with their university research offices and SSHRC officers to arrange for symbolic compensation in some instances. More work remains to be done in this respect, but even these small changes would not have been possible without institutional recognition of the value of FLEdGE partnership. While funding was limited (i.e., time bounded and amount awarded), the collaborations that developed the FLEdGE network predated the grant and evolved over six years to create new networks. In this way, research funding can serve as a kind of social investment by stimulating expansion of interactions with otherwise disconnected community networks. While FLEdGE-funded projects are officially completed, the relationships persist, and further work is being carried out within and beyond the partnerships fostered through the funding.

\section{Autonomy and adaptability: Networks addressing needs of project stakeholders}

FLEdGE produced a nimble, adaptable structure that enabled network participants to respond to context-specific changes and adapt to what was happening in the world and their immediate physical, social, and political environments. For instance, in 2017 when the Canadian government launched consultations to develop a national food policy, individuals and groups in the FLEdGE network were supported to contribute to the consultations, ensuring that they were able to represent their respective communities and corresponding positions. Similarly, when the COVID-19 pandemic began in 2020, different regional nodes were able to revise their research plans and respond to local needs. From the principal investigator to regional node leads and working group conveners, the deliberately decentralized structure of FLEdGE suggested that the administrative decision-makers (i.e., those who controlled the funding) trusted that projects would operate in a connected but independent manner, and this in turn allowed for greater participants' trust that those who had the administrative authority prioritized the partners' interests and needs, which was repeatedly noted by interview participants. Students and practitioners were encouraged to take initiative on various aspects of the research, from developing meaningful research questions to deciding on strategies to mobilize research findings, which minimized the risk of FLEdGE failing to respond to critical and timely research needs of respective nodes.

\footnotetext{
${ }^{5}$ In accordance with the standard SSHRC spending allowances, most of the budget was spent on student stipends, project coordination, and various meetings and information sharing efforts. Regional nodes had full autonomy over the funds distributed to them, so long as their spending met the SSHRC criteria.
} 


\section{Challenges: Empowering non-academic stakeholders}

Community-engaged research and intersectoral collaborations require a great deal of time and energy. The FLEdGE core team knew from previous projects that redundancy of representation was key to stability. That is, if multiple individuals and groups are participating and sharing knowledge from the same region and/or sector, and one has to step back for a time, the network can rely on others for important input and direction. To phrase this in modularity terms, in this network, components can operate both independently as well as interdependently. Still, maintaining participation over the course of several years is difficult in the climate of unreliable organizational funding and labour precarity. Continuity and stability were only possible because of team members with secure positions and dedicated staff - dedicated both in the sense that they worked primarily or exclusively with FLEdGE, and dedicated in their own commitment to the FLEdGE core principles. This highlights that a modular network can benefit from a substrate (or backbone) at its foundation for communication, interaction, and resources.

Despite a high level of awareness among academic researchers that power imbalances often plague community-engaged research (Knezevic et al., 2014), and the deliberate effort to acknowledge and minimize them, those imbalances did not disappear. In fact, such deliberate efforts, while often effective, also brought the imbalances to the surface and made them more salient. This is clearly demonstrated in the findings by much stronger interactions among academics, and weaker interactions among academics and community-based practitioners. This disconnect increased as the network grew in size and scope. That points in part to power-related tensions that surfaced because participants needed to balance the competing demands of FLEdGE and their workplaces. In academic settings, there remains a lack of institutional understanding of community-engaged research, and universities continue to undervalue this type of research (made most obvious through the academic "productivity" metrics that claim to measure research "impact," which we consider important, but not the sole or even the primary way to measure research impact). In practitioner settings, community needs are rightfully prioritized and contributions to research often happen 'off the side of the desk', meaning that community members' contributions to FLEdGE were not always part of their paid work time. This was further complicated by research funding regulations that make it difficult and sometimes impossible to adequately compensate community contributions to knowledge creation and mobilization. Nevertheless, the node leads worked closely with their institutions to push for greater flexibility on spending and compensate community partners when possible. 


\section{Conclusion}

In this paper we have presented a mixed-methods study of the FLEdGE intersectoral communityengaged research/action network and proposed that a modular approach can enhance networking opportunities and impact. Our collaborative insights focused on three key areas, including: crosspollination and the evolving network configurations; funding to support the interaction and decoupling of modules; and autonomy and adaptability for networks to address the needs of stakeholders. While the concept of modularity had not previously been used to describe these types of relationships, we propose that it can be considered as an organizing structure. Modular approaches in the context of community-engaged research networks enable diverse participants and their projects to operate with autonomy while also identifying and building on shared goals and objectives. Considering the complex social and ecological challenges within food systems, viable solutions demand collaboration along with diverse and critical perspectives that get to the root of equity and sustainability. Recognizing the diverse ways of knowing and the wealth of experiences of community-engaged researchers and practitioners, FLEdGE's modular nature led to the development of a dynamic network and impactful outcomes. Testament to this is evidence of the networks' growth over time, and its potential longevity. Moreover, as the funding for the FLEdGE network came to an end, many of the projects and the relationships took on a life of their own, leading to new research projects and contributing to building food movements across Canada and beyond. To be clear, the modular nature alone is not a guarantee for successful collaboration, but our findings suggest that it can facilitate a rewarding, adaptable partnership.

Beyond learning about the FLEdGE network, this research raised some important questions for future study. What is the right size and scope for an intersectoral research network? While there is no one answer to this question, our research showed that as the network grew, it was challenging to maintain connections among all the members. There are also questions of scale for networks that aim to be regionally focused yet bring on additional partners from other regions and internationally. We encourage others to reflect on these questions as a negotiation of process versus outcomes and to consider how best to maintain the relationships that are at the core of a network. We suggest that studying and critically reflecting on the structure and relationships that make up intersectoral research networks are vital parts of enhancing their operations and impacts. Formative and evaluative study should be built into these kinds of initiatives from the outset, and adequate energy and resources should be allocated to ensure their continuity. Furthermore, research networks might evaluate the impact of intersectoral community-engaged research after funding is completed, to assess the impact and evolution of the outcomes and relationships. Conducting an additional round of SNA, three to five years afterwards, might yield important results to demonstrate how relationships shift over time. 
Acknowledgements: We gratefully acknowledge the contributions from Kirstie Cadger and Karen Arnold who assisted with the social network analysis data analysis as well as Amanda Di Batista and Research Assistants Elena Christy and Heather Reid. We appreciate the time and energy of FLEdGE members who responded to the surveys, participated in the interviews, and played such an active role in our research/action projects. We also acknowledge support from the Laurier Centre for Sustainable Food Systems and financial contributions from the Social Sciences and Humanities Research Council of Canada (SSHRC).

\section{References}

About FLEdGE. (n.d.). FLEdGE. https://fledgeresearch.ca/about/.

Addy, N. A., Poirier, A., Blouin, C., Drager, N., \& Dubé, L. (2014). Whole-of-society approach for public health policymaking: a case study of polycentric governance from Quebec, Canada. Annals of the New York Academy of Sciences, 1331(1), 216-229.

Akama, Y. (2015). Being Awake to Ma: Designing in between-ness as a way of becoming with. CoDesign, 11(3-4), 262-274.

Albala, K. (Ed.). (2013). Routledge international handbook of food studies. New York: Routledge.

Alcantara, L., Harper, G., Keys, C., \& The Adolescent Medicine Trials Network for HIV/AIDS Interventions. (2015). 'There's gotta be some give and take': Community partner perspectives on benefits and contributions associated with community partnerships for youth. Youth and Society, 47(4), 462-85.

Andrée, P., Clark, J. K., Levkoe, C. Z., \& Lowitt, K. (Eds.). (2019). Civil society and social movements in food system governance. New York: Routledge.

Andrée, P., Kepkiewicz, L., Levkoe C. Z., Brynne, A., \& Kneen, C. (2016). Learning, food and sustainability in community-campus engagement: Teaching and research partnerships that strengthen the food sovereignty movement. In: J. Sumner (ed.). Learning, Food and Sustainability: Sites for Resistance and Change (pp.133-153). Palgrave.

Atkins, P., \& Bowler, I. R. (2016). Food in society: Economy, culture, geography. Routledge.

Baldwin, C. Y., \& Clark, K. B. (2000). Design rules: The Power of modularity. MIT Press.

Baquet, C. (2012). A model for bidirectional community-academic engagement (CAE): Overview of partnered research, capacity enhancement, systems transformation, and public trust in research. Journal of Health Care for the Poor and Underserved, 23(4), 1806-824.

Beckman, M., Penney, N., \& Cockburn, B. (2011). Maximizing the impact of community-based research. Journal of Higher Education Outreach and Engagement, 15(2), 83-103.

Blay-Palmer, A., Conaré, D., Meter, K., Di Battista, A., \& Johnston, C. (2019). Sustainable food system assessment: Lessons from global practice. Taylor and Francis. 
Blay-Palmer, A., Santini, G., Dubbeling, M., Renting, H., Taguchi, M., \& Giordano, T. (2018). Validating the city region food system approach: Enacting inclusive, transformational city region food systems. Sustainability, 10(5), 1680.

Bortolin, K. (2011). Serving ourselves: How the discourse on community engagement privileges the university over the community. Michigan Journal of Community Service Learning, $18(1), 49-58$.

Bradley, K., Gregory, M., Armstrong, J., Arthur, M., \& Porter, C. (2018). Graduate students bringing emotional rigor to the heart of community-university relations in food dignity. Journal of Agriculture, Food Systems, and Community Development, 8(A), 221-36.

Brady, J., Levkoe, C. Z., \& Szanto, D. (2015). Borders, boundaries, and becoming food studies: Looking back, pushing forward. Canadian Food Studies / La Revue Canadienne Des Études Sur l'alimentation, 2(1): 4-8.

Bringle, R. G., \& Hatcher, J. A. (2002). Campus-community partnerships: The terms of engagement. Journal of Social Issues, 58(3), 503-516.

Butcher, J., Bezzina, M., \& Moran, W. (2011). Transformational partnerships: A new agenda for higher education. Innovative Higher Education, 36, 29-40.

Campagnolo, D., \& Camuffo, A. (2010). The concept of modularity in management studies: A literature review. International Journal of Management Reviews, 12(3), 259-283.

Changfoot, N., Andrée, P., Levkoe C. Z., Nilson, M., \& Goemans, M. (2020). Engaged scholarship in tenure and promotion: Autoethnographic insights from the fault lines of a shifting landscape. Michigan Journal of Community Service Learning, 26(1), 239-264.

Checkoway, B. (2015). Research as community-building: Perspectives on the scholarship of engagement. Gateways: International Journal of Community Research and Engagement, $8(1), 139-149$.

Chupp, C., \& Joseph, M. (2010). Getting the most out of service learning: Maximizing student, university and community Impact. Journal of Community Practice, 18, 190- 212.

Curwood, S. E., Munger, F., Mitchell, T., Mackeigan, M., \& Farrar, A. (2011). Building effective community-university partnerships: Are universities truly ready? Michigan Journal of Community Service Learning, 17(2), 15-26.

Dempsey, S. E. (2010). Critiquing community engagement. Management Communication Quarterly, 24(3), 359-390.

Dorow, S., Stack-Cutler, H., \& Varnhagen, S. (2011). Community perspectives on partnering with the University of Alberta: The 2009 survey of local Edmonton organizations, University of Alberta, Edmonton, AB.

Flicker, S. (2008). Who benefits from community-based participatory research? A case study of the Positive Youth Project. Health Education and Behavior, 35(1), 70-86.

Frandsen, T. (2017). Evolution of modularity literature: A 25-year bibliometric analysis. International Journal of Operations and Production Management, 37(6), 703-747. 
Frank, L. (2014). Reflections of a food studies researcher: Connecting the community-universityPolicy divide....becoming the hyphens! Canadian Food Studies/La Revue canadienne des études sur l'alimentation, 1(1), 88-98.

Goemans, M., Levkoe C. Z., Changfoot, N., \& Andrée, P. (2018). Learning to "walk the talk": Reflexive evaluation in community-first engaged research. Engaged Scholar Journal: Community-Engaged Research, Teaching, and Learning, 4(2), 61-84.

Grain, K. M., \& Lund, D. (2016). The social justice turn: Cultivating "critical hope" in a time of despair. Michigan Journal of Community Service Learning, 23(1), 45-59.

Greenhalgh, T., Jackson, C., Shaw, S., \& Janamian, T. (2016). Achieving research impact through co-creation in community-based health services: Literature review and case study. The Millbank Quarterly, 94(2), 392-429.

Hart, M. A., Straka, S., \& Rowe, G. (2017). Working across contexts: Practical considerations of doing Indigenist/anti-colonial research. Qualitative Inquiry, 23(5), 332-342.

Incite! Women of Colour Against Violence. (2007). The revolution will not be funded. Duke University Press.

Israel, B., Schulz, A., Parker, E. A., \& Becker, A. E. (1998). Review of community-based research: assessing partnership approaches to improve public health. Annual Review of Public Health 19, 173-202.

Israel, B. A., Krieger, J., Vlahov, D., Ciske, S., Foley, M., Fortin, P., Guzman, J. R., Lichtenstein, R., McGranaghan, R., Palermo, A., \& Tang, G. (2006). Challenges and Facilitating Factors in Sustaining Community-Based Participatory Research Partnerships: Lessons Learned from the Detroit, New York City and Seattle Urban Research Centers. Journal of Urban Health, 83, 1022-1040.

Jagosh, J., Bush, P. L., Salsberg, J., Macaulay, A. C., Greenhalgh, T., Wong, G., Cargo, M., Green, L. W., Herbert, C. P., \& Pluye, P. (2015). A realist evaluation of community-based participatory research: partnership synergy, trust building and related ripple effects. $B M C$ Public Health, 15(1), 725.

Janes, J. E. (2016). Democratic encounters? Epistemic privilege, power, and community-based participatory action research. Action Research, 14(1), 72-87.

Kania, J., \& Kramer, M. (2011). Collective impact. Stanford Social Innovation Review, Winter 2011. http://leveragingourstrengths.ca/reading/collective_impact.pdf

Katz, J. S., \& Martin, B. R. (1997). What is research collaboration? Research Policy, 26(1), 1-18.

Keating, L., \& Sjoquist, D. (2000). The use of an external organization to facilitate universitycommunity partnerships. Cityscape: A Journal of Policy Development and Research, 5, $141-57$.

Kepkiewicz, L., Levkoe, C. Z., \& Brynne, A. (2018). “Community first” for whom? Reflections on the possibilities and challenges of community-campus engagement from the Community Food Sovereignty Hub. Engaged Scholar Journal, 4(2), 43-60. 
Knezevic, I., Blay-Palmer, A., Levkoe, C. Z., Mount, P., \& Nelson, E. (Eds.). (2017). Nourishing communities: From fractured food systems to transformative pathways. Springer.

Knezevic, I., Hunter, H., Watt, C., Williams, P., \& Anderson, B. (2014). Food insecurity and participation: A critical discourse analysis. Critical Discourse Studies 11(2), 230-245.

Koç, M., Sumner, J., \& Winson, A. (2016). Critical perspectives in food studies. Oxford University Press.

Lantz, P. M., Viruell-Fuentes, E., Israel, B. A., Softley, D., \& Guzman, R. (2001). Can communities and academia work together on public health research? Evaluation results from a community-based participatory research partnership in Detroit. Journal of Urban Health, 78(3), 495-507.

Latour, B. (2005). Reassembling the social: An introduction to actor-network-theory. Oxford University Press.

Law, J., \& Hassard, J. (1999). Actor network theory and after. Wiley-Blackwell.

Laforge, J. M., Dale, B., Levkoe, C. Z., \& Ahmed, F. (2020). The Future of agroecology in Canada: Embracing the politics of food sovereignty. Journal of Rural Studies, online, 1-9.

Levkoe C. Z., \& Kepkiewicz, L. (2020). Questioning the impact of impact: Evaluating community-campus engagement as contextual, relational and process-based. Michigan Journal of Community Service Learning, 26(1), 219-238.

Levkoe, C. Z., Ray, L., \& Mclaughlin, J. (2019). The Indigenous Food Circle: Reconciliation and resurgence through food in Northwestern Ontario. Journal of Agriculture, Food Systems, and Community Development, 9(B), 1-14.

Levkoe C. Z., \& Wilson, A. (2019). Policy engagement as prefiguration: Experiments in food policy governance through the national food policy dialogue in Canada. In: Andrée, P. Clark, J.K., Levkoe, C. Z., Lowitt, K. (Eds.). Civil Society and Social Movements in Food System Governance (pp. 101-123). Routledge, Series on Food, Society and Environment.

Levkoe, C. Z., \& Blay-Palmer, A. (2018). Food Counts: Food systems report cards, food sovereignty and the politics of indicators. Canadian Food Studies/La Revue canadienne des études sur l'alimentation, 5(3), 49-75.

Levkoe C. Z., \& Stack-Cutler, H. (2018). Brokering community-campus partnerships: An analytical framework. Gateways: International Journal of Community Research and Engagement, 11(1), 18-36.

Levkoe C. Z., Lowitt, K., \& Nelson, C. (2017). "Fish as food": Exploring a food sovereignty approach to small-scale fisheries. Marine Policy, 85, 65-70.

Levkoe C. Z., Andrée, P., Bhatt, V., Brynne, A., Davison, K., Kneen, C., \& Nelson, E. (2016). Collaboration for transformation: Community-campus engagement for just and sustainable food systems. Journal of Higher Education, Outreach and Engagement, 20(3), 23-61.

Lindamer, L., Lebowitz, B., Hough, R., Garcia, P., Aguirre, A., Halpain, M., Depp, C., \& Jest, D. (2009). Establishing an implementation network: Lessons learned from communitybased participatory research. Implementation Science, 4(17), 1-7. 
Lowitt, K., Levkoe, C. Z., \& Nelson, C. (2019). Where are the fish? Using a "fish as food" framework to explore the Thunder Bay area fisheries. Northern Review, 49, 93-118.

Marullo, S., \& Edwards, B. (2000). From charity to justice: The potential of universitycommunity collaboration for social change. American Behavioral Scientist, 43(5), 895912.

McBride, A. M., Brav, J., Menon, N., \& Sherraden, M. (2006). Limitations of civic service: Critical perspectives. Community Development Journal, 41(3), 307-320.

McNall, M., Reed, C., Brown, R., \& Allen, A. (2009). Brokering community-university engagement. Innovative Higher Education, 33, 317-31.

Mullett, J. (2015). Issues of equity and empowerment in knowledge democracy: Three community-based research examples. Action Research, 13(3), 248-261.

Naqshbandi, M., Harris, S. B., Macaulay, A. C., Comeau, J., Piché, J., \& Montour-Lazare, D. (2011). Lessons learned in using community-based participatory research to build a national diabetes collaborative in Canada. Progress in Community Health Partnerships: Research, Education, and Action, 5(4), 405-415.

Newman, M. E. J. (2006). Modularity and community structure in networks. Proceedings of the National Academy of Sciences, 103(23), 8577-8582.

Ochocka, J., \& Janzen, R. (2014). Breathing life into theory: Illustrations of community-based research-Hallmarks, functions, and phases. International Journal of Community Research and Engagement, 7(1), 18-33.

O’Meara, K., Eatman, T., \& Petersen, S. (2015). Advancing engaged scholarship in promotion and tenure: A roadmap and call for reform. Liberal Education, 101(3), 52-57.

Ostrom, E. (2010). Beyond markets and states: polycentric governance of complex economic systems. American Economic Review, 100(3), 641-72.

Peacock, D., Goemans, M., Kim, I., Andrée, P., Levkoe, C.Z., Changfoot, N., \& Kim, I. (2020). Accounting for community impact: Thinking across the spaces and times of a seven-year, pan-Canadian community-based research project. Michigan Journal of Community Service Learning, 26(1), 175-196.

Petri, A. (2015). Service-learning from the perspective of community organizations. Journal of Public Scholarship in Higher Education, 5, 93-110.

Phipps, D. (2011). A report detailing the development of a university-based knowledge mobilization unit that enhances research outreach and engagement. Scholarly and Research Communication, 2(2), 020502.

Phipps, D., Johnny, M., \& Wedlock, J. (2015). An institutional process for brokering community-campus research collaborations. Engaged Scholar Journal, 1(1), 69-86.

Reynolds, K., Block, D., \& Bradley, K. (2018). Food justice scholar-activism and activistscholarship: Working beyond dichotomies to deepen social justice praxis. ACME: An International E-Journal for Critical Geographies, 17(4), 988-998. 
Sandy, M., \& Holland, B. (2006). Different worlds and common ground: Community partner perspectives on campus-community partnerships. Michigan Journal of Community Service Learning, 13(1), 30-43.

Savan, S., \& Sider, D. (2003) Contrasting approaches to community-based research and a case study of community sustainability in Toronto, Canada. Local Environment, 8(3), 303-316.

Schwartz, K., Weaver, L., Pei, N., \& Miller, A. (2016). Community-campus partnerships, collective impact, and poverty reduction. Community Development, 47(2), 167-80.

Sheridan, M. P., \& Jacobi, T. (2014). Critical feminist practice and campus-community partnerships: A review essay. Feminist Teacher, 24(1-2), 138-150.

Shields, J., \& Evans, B. (2012). Building a policy-oriented research partnership for knowledge mobilization and knowledge transfer: The case of the Canadian Metropolis Project. Administrative Sciences, 2(4), 250-272.

Simba, M., \& Spring, A. (2017). Growing a garden in Kakisa. Northern Public Affairs, 5(1), 2426.

Smith, L. T. (2002). Decolonizing methodologies: Research and Indigenous Peoples. St. Martins Press.

Snowden, D. J., \& Boone, M. E. (2007). A leader's framework for decision making. Harvard Business Review, 85(11), 68-76.

Sobrero, P., \& Jayaratne, K. S. U. (2014). Scholarship perceptions of academic department heads: Implications for promoting faculty community engagement scholarship. Journal of Higher Education Outreach and Engagement, 18(1), 123-153.

Stoecker, R. (2008). Challenging institutional barriers to community-based research. Action Research, 6(1), 49-67.

Strand, K. J., Cutforth, N., Stoecker, R., Marullo, S., \& Donohue, P. (2003). Community-based research and higher education: Principles and practices. John Wiley and Sons.

Taylor, S. M., \& Ochocka, J. (2017). Advancing community-based research in Canada. International Journal of Knowledge-Based Development, 8(2), 183-200.

Tennyson, R. (2014). New mechanisms for brokering collaboration: The emergence of partnership brokering units and organisations. Betwixt and Between: The Journal of Partnership Brokering, 3.

Varcoe, C. (2006). Doing participatory action research in a racist world. Western Journal of Nursing Research, 28(5), 525-540.

Vernon, A., \& Ward, K. (1999). Campus and community partnerships: Assessing impacts and strengthening connections. Michigan Journal of Community Service Learning, 6(1), 30-37.

Wakefield, S. E. (2007). Reflective action in the academy: Exploring praxis in critical geography using a "food movement" case study. Antipode, 39(2), 331- 354.

Ward, K., \& Wolf-Wendel, L. (2000). Community-centered service learning: Moving from doing for to doing with. American Behavioral Scientist, 43(5), 767-780. 
Wright, K. N., Williams, P., Wright, S., Lieber, E., Carrasco, S. R., \& Gedjeyan, H. (2011). Ties that bind: Creating and sustaining community-academic partnerships. Gateways: International Journal of Community Research and Engagement, 4, 83-99. 